\title{
Double Beveling on Imaging: A Characteristic Feature of Entry and Exit Penetrating Injury Wound
}

\author{
Amit Agrawal $\quad$ VA Kiran Kumar ${ }^{1} \quad$ NA Sai Kiran ${ }^{1}$ \\ ${ }^{1}$ Department of Neurosurgery, Narayana Medical College Hospital, \\ Chinthareddypalem, Nellore, Andhra Pradesh, India \\ ${ }^{2}$ Department of Oral and Maxillofacial Surgery, Narayana Medical \\ College Hospital, Chinthareddypalem, Nellore, Andhra Pradesh, \\ India
}

\author{
Bathalapalli Penchalaiah Harsha Vinay ${ }^{2}$
}

Indian J Neurotrauma:2020;17:143-145

\begin{abstract}
Address for correspondence Amit Agrawal, MCh, Department of Neurosurgery, Narayana Medical College Hospital, Chinthareddypalem, Nellore, Andhra Pradesh 524003, India (e-mail: dramitagrawal@gmail.com,dramitagrawal@hotmail.com).
\end{abstract}
Abstract
Keywords
- craniofacial injury
- penetrating craniofacial injury
- beveling

Beveling of the calvarial bone is reported in firearm exit wounds and stabbing injuries in forensic literature. Beveling in entry wounds is rare. We report a case of a 27-yearold man who sustained a nonfatal penetrating craniofacial injury due to motorbike brake handle, and completely recovered after conservative management. We describe the characteristic inward as well outward beveling on imaging due the penetrating trajectory of the motorbike break handle.

\section{Introduction}

Atypical cranial vault lesions are characteristically described in forensic literature as sustained due to firearm injuries. ${ }^{1-3}$ Beveling of the calvarial bone usually occurs in firearm exit wounds and stabbing injuries ${ }^{1,3,4}$ Rarely beveling is described in firearm entry wounds ${ }^{1,3,4}$ and penetrating entry/exit wounds due to a sharp object. ${ }^{2}$ We report a case of a nonfatal penetrating craniofacial injury due to motorbike brake handle, managed conservatively, and discuss the characteristic imaging findings of beveling on computed tomography (CT) scan.

\section{Case Report}

A 27-year-old man was brought to the emergency department with an alleged history of road traffic accident while he was driving a motorbike and collided into the rear side of a lorry, and sustained penetrating injuries to the face as the motorbike handle hit his face. He was unconscious since the time of the accident and had multiple episodes of vomiting. There was no history of seizures and ear or nasal bleed. His general and systemic examination was normal. His Glasgow coma scale (GCS) score was 3 (E1V1M1) and his pupils were bilateral, equal and reacting. In view of poor GCS score he was intubated and kept on mechanical ventilation. Local examination showed a large laceration over the left malar region with visible fracture of the underlying bone. His blood investigations were normal. An urgent CT scan of the brain and face with bone window showed a small right basitemporal extradural hematoma with specks of pneumocephalus and small right temporal intracerebral hematoma (-Fig. 1A-C). There was no mass effect due to hematoma. Bone window showed fracture of the zygomatic bone and fracture of the right temporal bone with inward as well outward beveling ( - Fig.1D). The wound was thoroughly cleaned and sutured. In view of the small size of the hematoma, deep location, and no evidence of mass effect, it was decided to treat conservatively. The patient was continued with mechanical ventilation, antibiotics, antiepileptics, and antiedema measures. The patient responded well to conservative management and a follow-up CT scan suggested resolution in the size of hematoma. The patient made complete recovery and was doing well at follow-up.

\section{Discussion}

Penetrating craniofacial injuries are rare and account for approximately $0.4 \%$ of head injuries. ${ }^{5-9}$ A wide variety of mechanisms and objects can cause these penetrating craniofacial injuries. ${ }^{10-14}$ Apart from the injuries to facial skeleton, penetrating craniofacial injuries can lead to damage to orbit and its contents, cerebrospinal fluid (CSF) leak and its sequel (risk of meningitis or abscess), intracranial hematomas, injury to neurovascular structures, and retained foreign bodies. ${ }^{11,12,15-22}$
DOI https://doi.org/

10.1055/s-0040-1713319

ISSN 0973-0508.
CC2020 Neurotrauma Society of India
License terms

(ㅇ)(1) $\Theta \circledast$ 


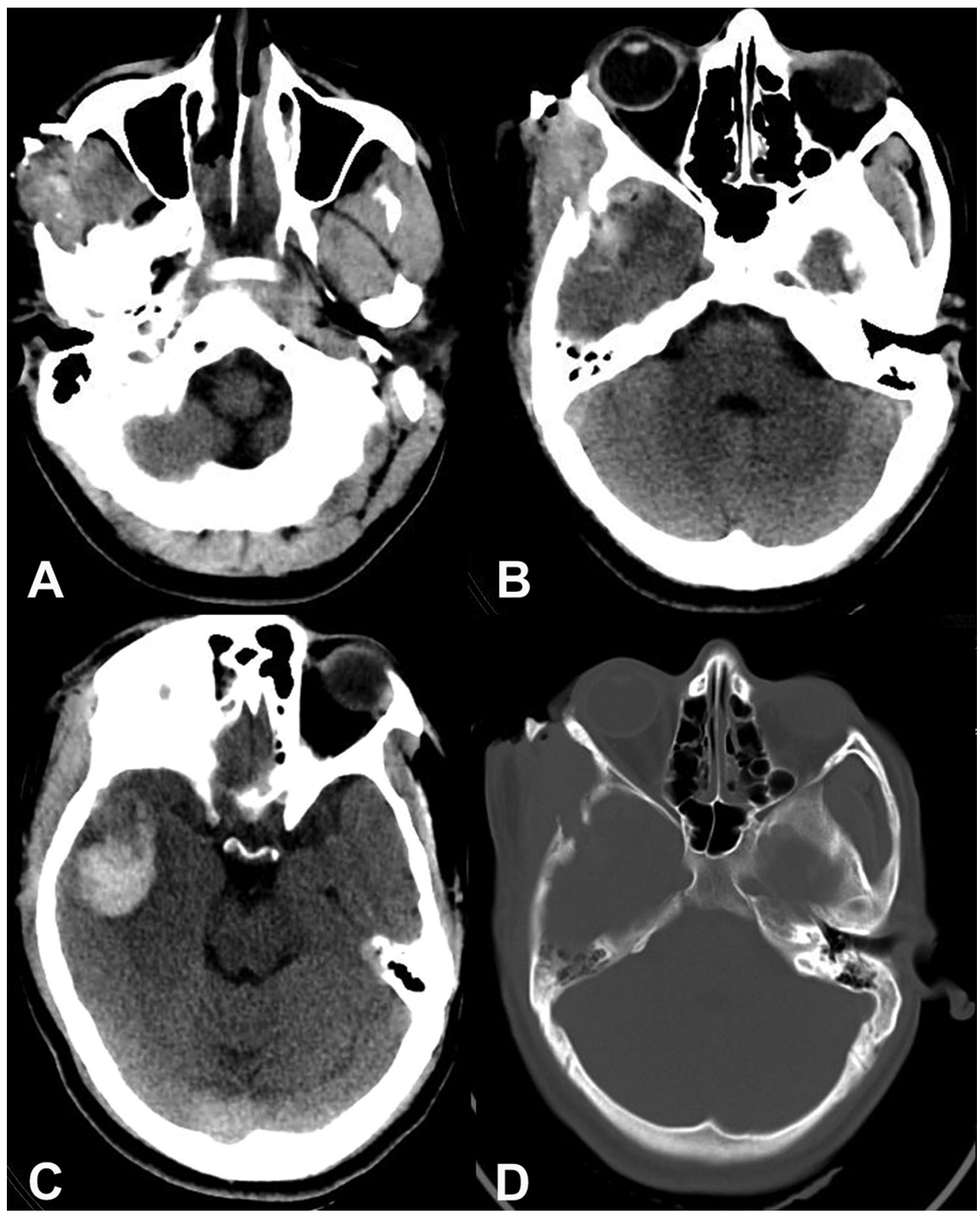

Fig. 1 Computed tomography scan with bone window showing (A) facture of zygomatic arch, (B) a small right basitemporal extradural hematoma with specks of pneumocephalus, (C) small right temporal intracerebral hematoma, and (D) fracture of the zygomatic bone and fracture of the right temporal bone with inward as well outward beveling fracture margins.

CT scan of the brain and face is the initial investigation of choice as it will provide the details of injuries, presence of intracranial injuries, trajectory of the penetrating object, and the presence of any retained foreign bodies. ${ }^{21,23,24}$ If necessary, a CT angiography can be useful to investigate the integrity of cerebral vasculature. ${ }^{24}$ The objectives of management of penetrating craniofacial injuries are safe and complete removal of penetrating objects, removal of any necrotic debris, repair of cranial defect to avoid CSF leak and its complications, evacuation of significant intracranial mass hematomas, and repair of vascular damage. ${ }^{10,21,25-28}$ The outcome of craniofacial penetrating injuries depends on the mechanism of injury and the underlying damage to neurovascular structures. ${ }^{10,17,22,24}$
If there is no major damage to these structures, the patients with penetrating craniofacial trauma have favorable outcome. . $^{10,17,22}$

\section{Conclusion}

Penetrating craniofacial injuries warrant a careful clinical and imaging evaluation of the wound and object trajectory. Characteristic on imaging are important to understand the type and trajectory of penetrating objects. Deep-seated lesions with smaller intracranial hematoma can be managed conservatively but need careful clinical and imaging follow-up. 


\section{Conflict of Interest}

None declared.

\section{References}

1 Quatrehomme G, Işcan MY. Bevelling in exit gunshot wounds in bones. Forensic Sci Int 1997;89(1-2):93-101

2 Delannoy Y, Colard T, Becart A, Tournel G, Gosset D, Hedouin $V$. Typical external skull beveling wound unlinked with a gunshot. Forensic Sci Int 2013;226(1-3):e4-e8

3 Quatrehomme G, Işcan MY. Analysis of beveling in gunshot entrance wounds. Forensic Sci Int 1998;93(1):45-60

4 Baik SO, Uku JM, Sikirica M. A case of external beveling with an entrance gunshot wound to the skull made by a small caliber rifle bullet. Am J Forensic Med Pathol 1991;12(4):334-336

5 Gennarelli TA, Champion HR, Sacco WJ, Copes WS, Alves WM. Mortality of patients with head injury and extracranial injury treated in trauma centers. J Trauma 1989;29(9):1193-1201, discussion 1201-1202

6 Hayashi Y, Fujisawa H, Tohma Y, Yamashita J, Inaba H. Penetrating head injury caused by bear claws: case report. J Trauma 2003;55(6):1178-1180

7 Anderson SA, Story PG. Case study of an orbital screwdriver injury. J Ophthalmic Nurs Technol 1996;15(3):103-104

8 Evans RJ, Richmond JM. An unusual death due to screwdriver impalement: a case report. Am J Forensic Med Pathol 1996;17(1):70-72

9 Ishikawa E, Meguro K, Yanaka K, et al. Intracerebellar penetrating injury and abscess due to a wooden foreign body-case report. Neurol Med Chir (Tokyo) 2000;40(9):458-462

10 Srinivas S, Agrawal A, Sandeep Y, Shrikhande NN. Massive penetrating craniofacial trauma due to polyvinyl chloride pipe. IJNS 2018;07:142-146

11 Agrawal A, Vijay M, Harsha J, Umamaheshwar Reddy V. Management of craniofacial injuries: a primer for residents. Romanian Neurosurgery 2014;21:341-347

12 Dubhashi SP, Choudhary K. Penetrating facial injury. Indian J Surg 2014;76(3):237-238

13 Salar G, Costella GB, Mottaran R, Mattana M, Gazzola L, Munari M. Multiple craniocerebral injuries from penetrating nails. Case illustration. J Neurosurg 2004;100(5):963

14 Zhang D, Chen J, Han K, Yu M, Hou L. Management of penetrating skull base injury: a single institutional experience and review of the literature. BioMed Res Int 2017;2017:2838167
15 Onyekwe LO, Ohaegbulam SC. Penetrating orbito-cranial and ocular cow-horn injuries. Niger J Clin Pract 2007;10(2): 177-179

16 Park SH, Cho KH, Shin YS, et al. Penetrating craniofacial injuries in children with wooden and metal chopsticks. Pediatr Neurosurg 2006;42(3):138-146

17 Karim T, Topno M. An unusual case of penetrating head injury in a child. J Emerg Trauma Shock 2010;3(2):197-198

18 Jain D, Aggarwal G, Lubana P, Moses S. Penetrating craniofacial arrow injury. J Neurosci Rural Pract 2010;1(1):17-19

19 Agarwal S, Gupta S. Hypohidrotic ectodermal dysplasia. Indian J Ophthalmol 1993;41:125-127

20 Demetriades AK, Papadopoulos MC. Penetrating head injury in planned and repetitive deliberate self-harm. Mayo Clin Proc 2007;82(5):536

21 Agrawal A, Pratap A, Agrawal CS, Kumar A, Rupakheti S. Transorbital orbitocranial penetrating injury due to bicycle brake handle in a child. Pediatr Neurosurg 2007;43(6):498-500

22 Agrawal A, Reddy VU, Kumar SS, Hegde KV, Rao GM. Transorbital orbitocranial penetrating injury with an iron rod. Craniomaxillofac Trauma Reconstr 2016;9(2):145-148

23 Walid MS, Yelverton JC, Robinson JS Jr. Penetrating orbital trauma with internal carotid injury. South Med J 2009;102(1):116-117

24 Lan Z, Richard SA, Ma L, Yang C. Nonmissile anterior skull-base penetrating brain injury: experience with 22 patients. Asian J Neurosurg 2018;13(3):742-748

25 Bunevicius A, Bareikis K, Kalasauskas L, Tamasauskas A. Penetrating anterior skull base fracture inflicted by a cow's horn. J Neurosci Rural Pract 2016;7(Suppl 1) :S106-S108

26 De Tommasi A, Cascardi P, De Tommasi C, Luzzi S, Ciappetta P. Emergency surgery in a severe penetrating skull base injury by a screwdriver: case report and literature review. World J Emerg Surg 2006;1:36

27 Chowdhury FH, Haque MR, Hossain Z, Chowdhury NK, Alam SM, Sarker MH. Nonmissile penetrating injury to the head: experience with 17 cases. World Neurosurg 2016;94:529-543

28 Schreckinger M, Orringer D, Thompson BG. La Marca F, Sagher O. Transorbital penetrating injury: case series, review of the literature, and proposed management algorithm. J Neurosurg 2011;114(1):53-61 